\title{
Oralna antikoagulantna terapija u elektivnim perkutanim koronarnim intervencijama
}

\author{
Miloje Tomašević, ${ }^{1,2}$, Srđan Aleksandrić ${ }^{1}$ \\ ${ }^{1}$ Klinika za kardiologiju, Klinički centar Srbije \\ ${ }^{2}$ Klinika za kardiologiju, Klinički centar Kragujevac; Medicinski fakultet, Univerzitet u Kragujevcu
}

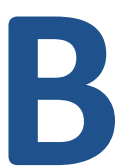

olesnici koji imaju atrijalnu fibrilaciju (AF), a pripremaju se za elektivnu perkutanu koronarnu intervenciju (PCI), zahtevaju kombinovanu dvojnu antitrombocitnu i oralnu antikoagulantnu terapiju koja se danas naziva trojna antitrombotska terapija. Kod većine ovih bolesnika trojna terapija je neophodna u cilju prevencije arterijskih tromboza i tromboembolijskih komplikacija, naročito moždanog tromboembolizma. Oralni antikoagulantni lekovi ne mogu da zamene dvojnu antitrombocitnu terapiju (DAT) u prevenciji stent tromboze jer u ovom procesu vodeću ulogu imaju trombociti. Sa druge strane, studije ACTIVE-W 1 BAFTA2 su pokazale da je oralna antikoagulantna terapija (OAKT) daleko superiornija u prevenciji moždanog tromboemboliza kod bolesnika sa AF u odnosu na DAT, jer u formiranju tromba u aurikuli leve pretkomore dominantnu ulogu ima fibrinogen, a ne aktivacija i agregacija trombocita.

Danas su nam na raspolaganju brojni novi antitrombocitni i antikoagulantni lekovi, što odluku o načinu njihove istovremene primene čini težom. Od antitrombocitnih lekova, pored dobro poznatih aspirina i klopidogrela, sve su više u upotrebi novi blokatori trombocitnih P2Y12 receptora (prasugrel i tikagrelor). Od oralnih antikoagulantnih lekova, pored vitamin K-antagonista (VKA), sve se više primenjuju direktni inhibitori trombina (dabigatran) i direktni inhibitori faktora Xa (rivaroxaban i apixaban). Način primene ovih lekova i njihove kombinacije se razlikuju pre planirane interventne procedure, u toku same procedure i nakon završene procedure.

Kod bolesnika sa AF petostruko raste rizik od moždanog tromboembolizma i isti je bez obzira na tip AF (paroksizmalna, perzistentna, permanentna $)^{3-6}$. Moždani tromboembolizam je praćen velikom smrtnošću (oko $25 \%$ ), dok se kod dve trećine bolesnika javlja trajna nesposobnost ${ }^{7-8}$. Taj rizik nije homogeno raspoređen kod svih bolesnika sa $A F$, već zavisi od nekoliko faktora koji povećavaju ovaj rizik. Prema najnovijim preporukama Evropskog udruženja kardiologa za lečenje AF (IA preporuka), za procenu rizika od moždanog tromboembolizma koristi se klinički skoring sistem CHA2DS2-VASc skor ${ }^{3-4}$. Na osnovu vrednosti ovog skora donosi se odluka o primeni OAKT kod bolesnika sa AF. Primena OAKT neophodna je kod AF bolesnika kod kojih je CHA2DS2-VASc skor $>1$, s tim da vrednosti INR-a (Internacionalni Normalizovan Odnos) treba da budu između 2 i 3 , osim kod bolesnika sa veštačkim zaliscima kod kojih vrednosti INR-a treba da budu između 2,5 i 3,5. Kod AF bolesnika čiji je CHA2DS2-VASc skor 0 , nije potrebna oralna antikoagulantna terapija ${ }^{3-4}$. Dakle, OAKT je indikovana kod svih bolesnika sa AF osim onih koji imaju mali rizik, mlađi su od 65 godina i nemaju dodatne tromboembolijske faktore rizika ${ }^{3-4}$. Istovremeno, pre uključivanja antikoagulantne terapije, potrebno je kod svih bolesnika sa AF proceniti i rizik od krvarenja, a za procenu ovog rizika koristi se HAS-BLED skor ${ }^{3-4}$. Vrednosti ovog skora $>3$ ukazuju na visok rizik od nastanak krvarećih komplikacija. Kod onih bolesnika sa AF koji ne žele da uzimaju OAKT može se razmotriti primena DAT (aspirin i klopidogrel ili samo aspirin) koja je, ipak, značajno manje efikasna u prevenciji moždanog trombembolizma od oralnih antikoagulanasa.

\section{Priprema bolesnika sa AF za elektivnu PCI}

Kod bolesnika koji su planirani za PCI neophodna je adekvatna medikamentna priprema koja podrazumeva primenu DAT (aspirin + blokatori P2Y12 receptora), najmanje 7 do 10 dana pre elektivne PCI. U CREDO studiji pokazano je da kombinovana primena aspirina u dozi od $100 \mathrm{mg}$ i udarne doze klopidogrela od 300 mg najmanje 6 sati pre planirane $\mathrm{PCl}$ značajno smanjuje učestalost velikih neželjenih kardiovaskularnih događaja (smrtni ishod, infarkt miokarda, moždani udar) ${ }^{9}$. Danas se vodi intenzivna rasprava o neophodnosti primene udarne doze novih antitrombocitnih lekova u akutnom koronarnom sindromu, u prvom redu prasugrela (ACCOAST studija) ${ }^{10}$. Što se tiče tikagrelora, korist od prehospitalne u odnosu na hospitalnu primenu udarne doze ovoga leka od $180 \mathrm{mg}$ kod bolesnika sa akutnim infarktom miokarda sa elevacijom ST segmenta (STEMI) očekujemo uskoro iz rezultata ATLANTIC studije ${ }^{11}$. Međutim, nema podataka o efikasnosti i bezbednosti novih antitrombocitnih lekova kod bolesnika sa hroničnom (stabilnom) koronarnom bolešću koji se podvrgavaju elektivnoj PCl jer do sada nije sprovedena nijedna randomizovana klinička studija koja bi ispitala efekte ovih lekova kod stabilnih bolesnika.

Kod bolesnika sa AF koji su planirani za elektivnu PCI, neophodna je primena DAT koja podrazumeva kombinaciju aspirina $100 \mathrm{mg}$ i klopidogrela $75 \mathrm{mg}$ dnevno. Tikagrelor i prasugrel se koriste kod AF bolesnika planiranih za elektivnu PCl samo ukoliko je postojala stent tromboza dok je bolesnik bio na terapiji klopidogrelom. U visoko rizičnim 


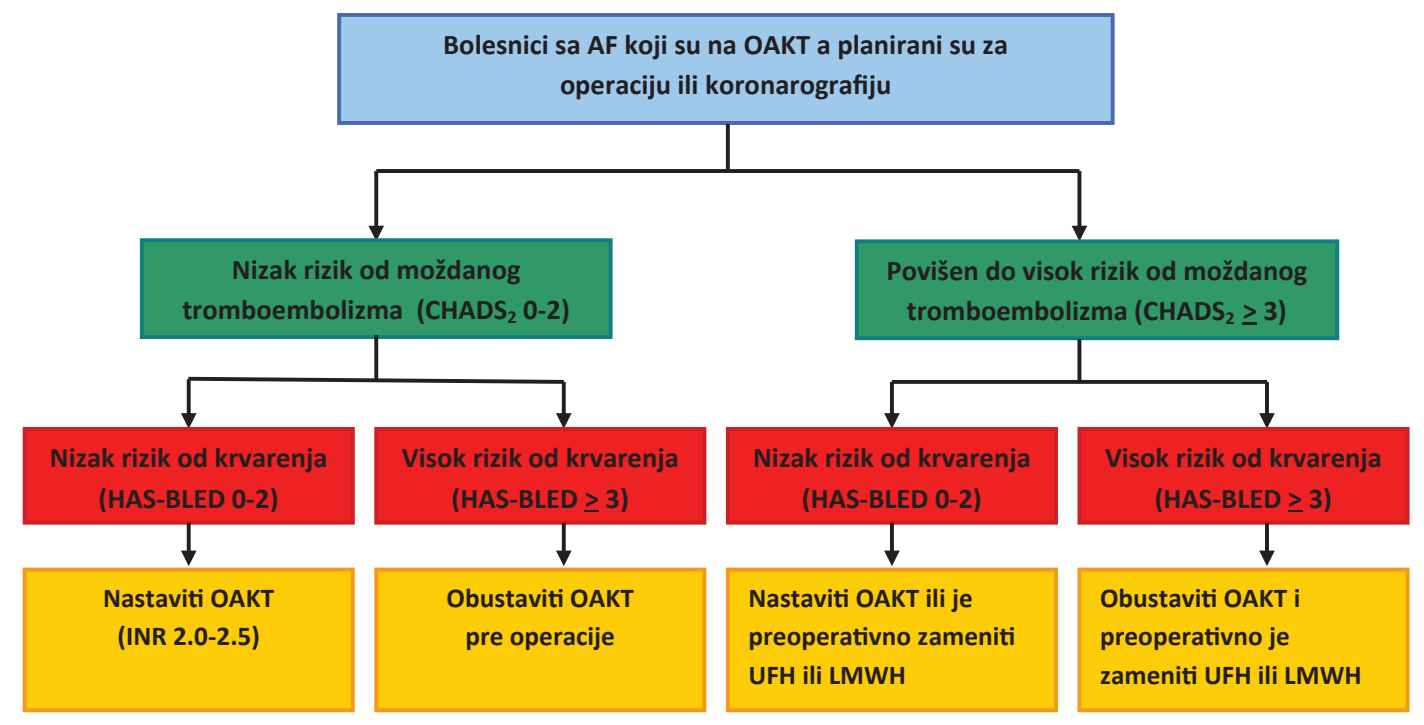

OAKT - oralna antikoagulantna terapija; UFH - nefracionisani heparin;

LMWH - niskomolekularni heparin

Slika 1. Preporuke za primenu oralne antikoagulantne terapije (OAKT) kod bolesnika sa

AF koji su planirani za operaciju ili koronarografiju ${ }^{3-4}$

situacijama, kao što je stentiranje glavnog stabla leve koronarne arterije, izvođenje $\mathrm{PCl}$ kod visokorizičnih bolesnika za trombozu stenta ili kod bolesnika sa dijabetesom, potrebno je takođe razmotriti primenu tikagrelora ili prasugrela ${ }^{12}$. U trenutku kada anatomija koronarnih arterija nije poznata ne preporučuje se priprema bolesnika za intervenciju klopidogrelom. Tek nakon inicijalne koronarografije, poznate koronarne anatomije i donesene odluke o datumu intervencije treba planirati početak primene drugog antitrombocitnog leka, najčešće klopidogrela. Kod niskorizičnih bolesnika koji su planirani za elektivnu $\mathrm{PCl}$ ne preporučuje se primena prasugrela ili tikagrelora ${ }^{12}$. Koronarna angiografija spada u intervencije sa malim rizikom od krvarenja. Kod bolesnika sa AF antikoagulantni lek treba isključiti 5 dana pre intervencije i sačekati da vrednost INR-a padne ispod 1,5 posle čega je izvođenje interventne procedure bezbednije. Ukoliko je dan pre intervencije INR i dalje visok $(>1,5)$, treba razmotriti dodavanje male doze vitamina $\mathrm{K}$ u dozi od 1 do $2 \mathrm{mg}$. Ukoliko bolesnik sa AF uzima neki od novih oralnih antikoagulantnih lekova (NOAC), onda lek treba prekinuti 24 sata pre izvođenja elektivne PCl. Ukoliko kod ovih bolesnika postoji visok rizik od krvarenja, NOAC treba prekinuti 48 sata pre izvođenja PCl. lako određivanje aPTT-a i PT-a predstavlja semikvantitativno određivanje inhibicije faktora Xa i trombina, odlaganje intervencije do normalizacije ovih faktora nije u praksi dokazano kao korisno ${ }^{13}$. Postavlja se pitanje da li bolesniku sa AF koji uzima OAKT radi prevencije ishemijskog šloga treba obustaviti OAKT ukoliko ide na operaciju ili koronarografiju. Prema preporukama Evropskog udruženja kardiologa za lečenje AF (Slika 1), bolesnici koji imaju nizak rizik od moždanog tromboembolizma (CHADS2 0-2) i nizak rizik od krvarenja (HAS-BLED 0-2), mogu da nastave da uzimaju OAKT, $s$ tim da vrednosti INR-a moraju biti na donjoj granici terapijskog opsega (INR 2.0-2.5) (-4 $^{3-}$ Kod bolesnika sa AF koji imaju povišen do visok rizik od moždanog tromboembolizma (CHADS2 > 3) i visok rizik od krvarenja (HAS-
BLED > 3) preporučuje se zamena OAKT parenteralnom terapijom nefrakcionisanim (UFH - unfractioned heparin) ili niskomolekularnim heparinom (LMWH - low-molecular weighted heparin) najmanje 24 sata pre operacije ili koronarografije. Nefrakcionisani heparin se daje u vidu kontinuirane intravenske infuzije. Kod bolesnika sa mehaničkim valvulama neophodna je intravenska infuzija UFH, a smatra se da je bolesnik u terapijskim granicama dobre zaštite ukoliko je aPTT 1,5 do 2 puta veći od njegove gornje normalne granice. Infuzija se prekida 4 sata pre intervencije ukoliko želimo kompletnu eliminaciju, ili kraće 1 do 2 sata ukoliko želimo da delovanje UFH prestane u toku samog izvođenja procedure. U slučaju LMWH, poslednja doza se daje 24 sata pre planirane $\mathrm{PCl}^{14}$.

Važno je napomenuti da je potrebna potpuna individualizacija antitrombocitne i antikoagulantne terapije kod AF bolesnika koji su imali akutni koronarni sindrom (AKS) na osnovu aterotrombotskog, trombooembolijskog rizika i rizika od krvarenja. Oni se određuju na osnovu postojećih GRACE, CHA2DS2-VASc i HAS-BLED skorova ${ }^{14}$.

\section{Postupci u toku same intervencije}

Trojna antitrombotska terapija udružena je sa značajnim povećanjem jednogodišnjeg rizika od krvarenja ${ }^{15}$. Do danas nema velike randomizovane studije koja bi ukazala na bezbednost i efikasnost trojne terapije, ali se ona ipak koristi u svakodnevnoj praksi. Manje studije ukazuju na porast rizika od krvarenja, ali kratkotrajna primena je izgleda prihvatljiva terapijska opcija pod uslovom da vrednosti INR-a budu na donjoj granici terapijskog okvira $(2-2,5)$. Kako kod ovih bolesnika izabrati tip koronarnog stenta (metalni stent vs. stent sa oslobađanjem leka), koliko je trajanje trojne antitrombotske terapije i koju terapiju bolesnik treba da dobija ukoliko ide na PCI ili hirušku revaskularizaciju miokarda ostaju ključna pitanja u razmatranju rizika od stent tromboze, trombo- 
Tabela 1. Preporuke za primenu trojne antitrombotske terapije nakon primarne ili elektivne PCI kod bolesnika sa AF koji imaju povišen ili visok rizik od moždanog tromboembolizma (CHADS2 > 1$)^{3-4}$

\begin{tabular}{|c|c|c|c|}
\hline $\begin{array}{l}\text { Rizik od } \\
\text { krvarenja }\end{array}$ & $\begin{array}{l}\text { Kliničke } \\
\text { indikacije }\end{array}$ & $\begin{array}{l}\text { Tip } \\
\text { stenta }\end{array}$ & Način primene trojne antitrombotske terapije \\
\hline \multirow{3}{*}{$\begin{array}{l}\text { Nizak ili } \\
\text { povišen } \\
\text { rizik } \\
\text { (HAS-BLED } \\
0-2 \text { ) }\end{array}$} & $\begin{array}{l}\text { Elektivna } \\
\text { PCl }\end{array}$ & BMS & $\begin{array}{l}1 \text { mesec: trojna terapija (OAKT (INR 2.0-2.5) + aspirin } 100 \mathrm{mg} / \mathrm{d}+\text { klopidogrel } 75 \mathrm{mg} / \mathrm{d} \text { ) } \\
\text { Do godinu dana: OAKT (INR 2.0-2.5) + klopidogrel } 75 \mathrm{mg} / \mathrm{d} \text { ili aspirin } 100 \mathrm{mg} / \mathrm{d} \\
\text { Nakon godinu dana: samo OAKT (INR 2.0-3.0) }\end{array}$ \\
\hline & $\begin{array}{c}\text { Elektivna } \\
\mathrm{PCl}\end{array}$ & DES & $\begin{array}{l}\text { 3-6 meseci: trojna terapija (OAKT (INR 2.0-2.5) + aspirin } 100 \mathrm{mg} / \mathrm{d}+\text { klopidogrel } 75 \mathrm{mg} / \mathrm{d} \text { ) } \\
\text { Do godinu dana: OAKT (INR 2.0-2.5) + klopidogrel } 75 \mathrm{mg} / \mathrm{d} \text { ili aspirin } 100 \mathrm{mg} / \mathrm{d} \\
\text { Nakon godinu dana: samo OAKT (INR 2.0-3.0) }\end{array}$ \\
\hline & AKS & $\begin{array}{l}\text { BMS/ } \\
\text { DES }\end{array}$ & $\begin{array}{l}6 \text { meseci: trojna terapija (OAKT (INR 2.0-2.5) + aspirin } 100 \mathrm{mg} / \mathrm{d}+\mathrm{k} \\
\text { Do godinu dana: OAKT (INR 2.0-2.5) + klopidogrel } 75 \mathrm{mg} / \mathrm{d} \text { ili aspirir } \\
\text { Nakon godinu dana: samo OAKT (INR 2.0-3.0) }\end{array}$ \\
\hline \multirow{2}{*}{$\begin{array}{l}\text { Visok rizik } \\
(\text { HAS-BLED } \\
\geq 3)\end{array}$} & $\begin{array}{c}\text { Elektivna } \\
\text { PCl }\end{array}$ & BMS & $\begin{array}{l}\text { 2-4 nedelje: trojna terapija (OAKT (INR 2.0-2.5) + aspirin } 100 \mathrm{mg} / \mathrm{d}+\text { klopidogrel } 75 \mathrm{mg} / \mathrm{d} \text { ) } \\
\text { Dozivotno samo OAKT (INR 2.0-3.0) }\end{array}$ \\
\hline & AKS & BMS & $\begin{array}{l}4 \text { nedelje: trojna terapija (OAKT (INR 2.0-2.5) + aspirin } 100 \mathrm{mg} / \mathrm{d}+\text { klopidogrel } 75 \mathrm{mg} / \mathrm{d} \text { ) } \\
\text { Do godinu dana: OAKT (INR 2.0-2.5) + klopidogrel } 75 \mathrm{mg} / \mathrm{d} \text { ili aspirin } 100 \mathrm{mg} / \mathrm{d} \\
\text { Dozivotno samo OAKT (INR 2.0-3.0) }\end{array}$ \\
\hline
\end{tabular}

BMS - metalni stent (bare-metal stent); DES - stent sa oslobađanjem leka (drug-eluting stent)

embolijskih događaja i krvarenja. Na osnovu konsenzus dokumenta Evropskog udruženja kardiologa o antitrombocitnoj terapiji kod bolesnika sa AF kojima je ugrađen koronarni stent, danas ipak postoje smernice o kombinovanju i pravilnom doziranju ovih lekova (Tabela 1$)^{3-4}$ Kod bolesnika sa AF preporučuje se ugradnja metalnih stentova (BMS - bare metal stent), dok se stentovi sa oslobađanjem leka (DES - drug eluting stent) primenjuju u strogo indikovanim slučajevima (dijabetes, mali krvni sudovi, hronične totalne okluzije) pod uslovom da je rizik od krvarenja nizak (HAS-BLED 0-2). Kod bolesnika sa AF koji imaju visok rizik od krvarenja (HAS-BLED > 3) ugradnja DES-a se ne reporučuje. Kod bolesnika sa AF čiji je CHADS2 > 1 i imaju nizak rizik od krvarenja (HASBLED 0-2) trojna antitrombotska terapija (INR 2.0-2.5) daje se prvih mesec dana nakon ugradnje BMS, 3-6 meseci nakon ugradnje DES i 6 meseci nakon AKS bez obzira na tip ugrađenog stenta. Kod bolesnika koji imaju visok rizik od krvarenja (HAS-BLED > 3) trojna antitrombotska terapija daje se prve $2-4$ nedelje nakon $\mathrm{PCl}$ i 4 nedelje nakon $\mathrm{AKS}^{3-4}$.

Transradijalni pristup, naročito prilikom izvođenja elektivne $\mathrm{PCl}$, smanjuje rizik od krvarenja na mestu punkcije. Smanjenje rizika od krvarećih komplikacija primenom transradijalnog pristupa veće je nego primenom bilo koje strategije u antikoagulantnoj terapiji. Rizik od tromboembolizma ili od dugotrajne primene trojne antitrombotske terapije i krvarenja može uticati i na odluku o načinu miokardne revaskularizacije kod višesudovne koronarne bolesti ( $\mathrm{PCl}$ ili aorto-koronarni bypass operacija). Hiruška revaskularizacija miokarda naravno u ovim uslovima ima prednosti.

\section{Ponovno uvođenje antikoagulantne terapije posle uspešne $\mathrm{PCI}$}

Prekid redovne OAKT i njeno ponovno uvođenje nije bez rizika. Ponovno uvođenje OAKT (VKA) je praćeno i rebound efektom, tako da je protrombotski efekat ovih lekova prisutan prvih nekoliko dana po njihovom uvođenju. Kod AF bolesnika sa niskim rizikom od tromboembolij- skih komplikacija, ali i kod većine visokorizičnih bolesnika nije neophodna „bridging” terapija ukoliko je prekid OAKT kratak. Ukoliko bolesnik već uzima OAKT više od mesec dana, verovatnoća da je došlo do rezolucije potencijalnog tromba u levoj pretkomori je velika, pa kratkotrajni prekid OAKT da bi se izvela PCI ne nosi sa sobom visok rizik od tromboembolijskih komplikacija. Ukoliko je hemostaza kompletna i izvodi se odmah nakon PCl, NOAC mogu ponovo da se uvedu 6 do 8 sati nakon $\mathrm{PCl}$ ili nakon postizanja stabilne hemostaze ${ }^{13}$. Studija PRODIGY je pokazala da dugotrajna DAT (duža od 24 meseca) nema prednosti u odnosu na kartkotrajnu DAT (do 6 meseci) bez obzira na tip ugrađenog stenta ${ }^{16}$.

Rizik od dugotrajne trojne antitrombotske terapije nakon $\mathrm{PCl}$ je neprihvatljiv. WOEST studija, jedina randomizovana studija sa trojnom antitrombotskom terapijom, pokazala je gotovo duplo povećanje rizika od krvarenja u odnosu na kombinovanu terapiju VKA i klopidogrelom. U grupi bolesnika koji su dobijali kombinovanu terapiju VKA i klopidogrelom čak je i mortalitet bio značajno manji. To je dovelo do praktičnih implikacija da se trojna terapija koristi što kraće ili da se, ukoliko je to ikako moguće, u potpunosti izbegne nakon $\mathrm{PCl}$ i zameni kombinovanom terapijom VKA i klopidogrelom, eventualno aspirinom umesto klopidogrela. Rezultati su takvi da je dovoljno obustaviti aspirin kod 4 bolesnika sa AF i ugrađenim koronarnim stentom da bi se sprečila jedna krvareća epizoda. To su mala i minorna krvarenja, ali su u kliničkom smislu ipak značajna. Da bi se sprečilo jedno veliko krvarenje, treba obustaviti aspirin kod 40 ovakvih bolesnika. Sa druge strane, i kombinovana terapija VKA i klopidogrelom povećava rizik od krvarenja u odnosu na DAT ili samo OAKT. Trojna antitrombotska terapija sa NOAC najmanje povećava rizik od krvarenja17. U RELY studiji koja je ispitivala efekte dabigatrana kod AF bolesnika pokazano je da dodavanje jednog ili dva antitrombocitna leka povećava rizik od krvarenja za 60 ili $130 \%$. Prednosti koje imaju NOAC u odnosu na VKA verovatno se održavaju i u dvojnoj i trojnoj terapiji, ali ova hipoteza do danas nije potvrđena u kliničkim studijama ${ }^{14}$. 
Kod bolesnika koji su na hroničnoj terapiji VKA koronarna intervencija može biti bezbedna i bez „bridginga“, ali i bez dodavanja heparina. Da li se isto može primeniti na NOAC, nije potpuno jasno, ali analogija sa fondaparinoxom i učestalom trombozom katetera u OASIS studiji ukazuje na to da možda NOAC nisu dovoljno bezbedni za izvođenje $\mathrm{PCl}$. Zbog toga su potrebne nove randomizovane kliničke studije koje bi razrešile postojeće dileme.

Potrebna je potpuna individualizacija antitrombocitne i antikoagulantne terapije nakon AKS na osnovu aterotrombotskog, trombooembolijskog i rizika od krvarenja. Oni se određuju na osnovu postojećih GRACE, CHA2DS2VASc i HAS-BLED skorova ${ }^{14}$.

\section{Literatura}

1. Connolly S, Pogue J, Hart R, et al. ACTIVE Writing Group of the ACTIVE Investigators. Clopidogrel plus aspirin versus oral anticoagulation for atrial fibrillation in the Atrial fibrillation Clopidogrel Trial with Irbesartan for prevention of Vascular Events (ACTIVE W): a randomised controlled trial. Lancet 2006;367:1903-1912.

2. Mant J, Hobbs FD, Fletcher K, et al. Warfarin versus aspirin for stroke prevention in an elderly community population with atrial fibrillation (the Birmingham Atrial Fibrillation Treatment of the Aged Study, BAFTA): a randomised controlled trial. Lancet 2007;370(9586):493-503.

3. Camm AJ, Kirchhof P, Lip GYH, et al. The Task Force for the Management of Atrial Fibrillation of the European Society of Cardiology (ESC). Guidelines for the management of atrial fibriIlation. European Heart Journal 2010:31;2369-2429.

4. Camm AJ, Lip GYH, De Caterina R, et al. 2012 focused update of the ESC Guidelines for the management of atrial fibrillation. An update of the 2010 ESC Guidelines for the management of atrial fibrillation. Developed with the special contribution of the European Heart Rhythm Association. European Heart Journal 2012;33:2719-2747.

5. Wolf PA, Abbott RD, Kannel WB. Atrial fibrillation as an independent risk factor for stroke: the Framingham Study. Stroke 1191:22(8):983-988.

6. Rosamond W, Flegal K, Furie K, et al. Heart disease and stroke statistics-2008 update: a report from the American Heart
Association Statistics Committee and Stroke Statistics Subcommittee. Circulation 2008;117(4):e25-146.

7. Hart RG, Pearce LA, Rothbart RM, et al. Stroke with intermittent atrial fibrillation: incidence and predictors during aspirin therapy. Stroke Prevention in Atrial Fibrillation Investigators. J Am Coll Cardiol 2000;35:183-187.

8. Lin HJ, Wolf PA, Kelly-Hayes M, et al. Stroke severity in atrial fibrillation. The Framingham Study. Stroke 1996; 27:1760-1764.

9. Steinhubl SR, Berger PB, Mann JT 3rd, et al. Early and sustained dual oral antiplatelet therapy following percutaneous coronary intervention: a randomized controlled trial, JAMA 2003;289:(8):987.

10. Montalescot G, Bolognese L, Dudek D, et al. Pretreatment with Prasugrel in Non-ST-segment elevation Acute Coronary Syndromes, N Engl J Med 2013;369(11):999-1010.

11. Navarese EP, Buffon A., Kozinski M, et al. A critical overview on ticagrelor in acute acute coronary syndromes, QJM 2013;106(2):105-115.

12. Montalescot G, Sechtem U, Achenbach S, et al. ESC guidelines on the management of stable coronary artery disease. The Task Force on the management of stable coronary artery disease of the European Society of Cardiology. Eur Heart J 2013;34(38):2949-3003.

13. Heidbuchel H, Verhamme P, Alings M, et al. European Heart Rhythm Association Practical Guide on the use of new oral anticoagulants in patients with non-valvular atrial fibrillation, Europace 2013;15,625-651.

14. Cook BW. Anticoagulation Management. Semin Intervent Radiol, 2010;27(4):360-367.

15. Hälg C, Brunner-La Rocca HP, et al. Early and late increased bleeding rates after angioplasty and stenting due to combined antiplatelet and anticoagulanttherapy. Eurolntervention 2009;5(4):425-431.

16. Valgimigli M, Campo G, Monti M, et al. Short- Versus Long-Term Duration of Dual-Antiplatelet Therapy After Coronary Stenting for the Prolonging Dual Antiplatelet Treatment After Grading Stent-Induced Intimal Hyperplasia Study (PRODIGY) Investigators, Circulation 2012;125:2015-2026.

17. Dewilde WJM, Oirbans T, Verheugt FWA, et al. Use of clopidogrel with or without aspirin in patients taking oral anticoagulant therapy and undergoing percutaneous coronary intervention: an open-label, randomised, controlled trial. Lancet 2013,381:11071115. 